\title{
DESIGN AND ANALYSIS OF FOG REMOVAL SYSTEM FOR HELMET
}

\author{
Vivek Verma $^{1}$, Ashwani Sharma ${ }^{2}$, Ashwini Kumar Shrivastava ${ }^{3}$, Himal Hazra ${ }^{4}$ \\ ${ }^{1}$ Assistant Professor, Mechanical and Automation Engineering, Amity University, U.P, India \\ ${ }^{2}$ Assistant Professor, Mechanical and Automation Engineering, Amity University, U.P, India \\ ${ }^{3}$ Student, Mechanical and Automation Engineering, Amity University, U.P, India \\ ${ }^{4}$ Student, Mechanical and Automation Engineering, Amity University, U.P, India
}

\begin{abstract}
This paper deals with the design and analysis of fog removal system for motorcycle helmet. The system consists mainly of a resistive wire for thermal convection between the heating element and the helmet visor. When electrical voltage is applied to the heating element, it will create a temperature difference across the helmet visor. The model is designed and thermal analysis has been carried out using Ansys. The analysis shows efficient mist removal from the visor in few minutes.
\end{abstract}

Keywords: - Fog Removal System, Helmet, Thermal Convection, Thermal Analysis

\section{INTRODUCTION}

The continuous development of automobile industry has revolutionized new invention, not only for the safety, but also for comfort of the rider. In winter most of the northern India suffers from foggy morning with less to none visibility. The concern over the safety of vehicle drivers in foggy weather has pushed for invention of new equipment that can save lives. This project is based on the working of a fog removal system, which uses a heating element system, and bike battery for its energy source the design is simple and hence cost effective.

\section{BACKGROUND}

During winter we often face fog. Fog is a natural phenomenon in which cloud water or ice crystal stays in a suspended stagnant motion heavily influenced by nearby water body or by low atmospheric temperature, fog reduces visibility to up to less than $1 \mathrm{~km}$. Formation of fog starts from when water vapor condenses into tiny water droplet, as to how water is added, by convergence into upward motion precipitation from above, daytime heating evaporation, transpiration from plants, trees, cool air moving over warmer water. Fog occurs at a relative humidity near $100 \%$, this occurs by either addition of water vapor or falling in ambient temperature.

Fog is a natural phenomena but it also cause major problem for riders and vehicle drivers, Cloud, fog, mist droplets are very small, their mean diameter is actually around 10- 15 micron, but the question lies why rider or driver have problem in seeing while water is transparent in nature? Answer will be as water droplets are small and large in number, light ray scatters around them neither reflecting nor refracting, and hence it only gives a sense of vision nothing clear at all. Now due this the water droplets which is stagnant in nature sticks to the visor of the rider now fogging on the visor occurs due to drastic temperature difference in inside the visor and the ambient temperature, when the rider breathes he exhales hot air through nose or mouth the visor being cold as it has been exposed due to cold weather comes in contact with hot air, the air condenses on the visor due to which it fogs up the visor and hence render difficulties to the rider.

Hence to remove this difficulty various ideas are being implemented for car rider they have various techniques to remove fogging difficulties comes to the motor cycle riders, now this is where our project throws light fog removal system for helmet. There are various methods to remove fog from helmet visor like heated element, sonar or UV ray detection or an externally fitted ventilation system with forced exhaust system. In this project we have opted for heated visor system with a nickel plated steel wire heating the visor externally to remove the fog formation and to render clear visibility. The project will run its course in various design and analysis procedure like analysis for heat producing body, thermal analysis (steady state, transient state) analysis, CFD analysis, airflow analysis to check whether the heating element proves viable in cold conditions.

\section{SELECTION AND ANALYSIS OF THE HEATING MATERIAL}

First we thought of using Nichrome (Ni, Fe, Cr alloy) as it is what they use basically in all heating elements, we obtained one from an old thermo heater but we did not expect the heat to be too high that it started melting the polycarbonate visor on a 12 volt D.C. source. As Nichromeholds a resistivity of $100 \times 10^{\wedge}-8 \mathrm{ohm}$ and a very less conductivity of $0.10 \times 10^{7} / \mathrm{ohm}$-meter. The electrical resistance depends on the length area as well as on the material of the wire now the question was how to choose an element that will provide a higher resistance but at the same time does no harm to the visor.The formula which describes the resistance of a wire is Resistance $=$ resistivity $\mathrm{x}$ length/area $\mathrm{R}=\rho(1 / \mathrm{a})$ 
$\rho=$ resistivity of the material given,

$1=$ length of the material given,

$\mathrm{a}=$ area of the material given,

After various considerations we stumbled upon the idea of wire we were using wire hence thought of guitar a few guitar uses nickel plated steel which fall right into our goldilocks region as steel provides strength and less thermal expansion and also relatively high temperature without burning out the visor but when steel plated with nickel gives it more strength, corrosion resistivity and increases conductance of electricity.

In metallurgy, stainless steel is defined as a steel alloy with a minimum composition of $11 \%$ chromium content by mass [3]. Stainless steel does not stains neither corrodes nor rusts as easily as ordinary steel but not only its stain-proof. It is also called corrosion resistant steel when the alloy type and grade are not mentioned,[3] especially in the aviation industry, there are different types of grades and surface finishes of stainless steel to suit the environment to which the material will be subjected in its machine life.

\section{ANALYSIS AND SPECIFICATIONS OF}

\section{POLYCARBONATE ACRYLIC VISOR}

Polycarbonate properties are higher than its predecessor and it does provide a high impact strength and excellent strength retention at high temperatures. It also possesses high tensile, shear, and flexural strength. It has high modulus of elasticity and low deformation under load which helps it to retain a tough structure. It has low coefficient of thermal expansion and hence doesn't expand much on elevated temperature. Further it also possesses good electrical insulation properties and is very easy to fabricate $\&$ machine stuff. Acrylic helps in increasing the visibility by $3 \%$ up to $92 \%$.Acrylic is a type of a polymer called poly (methyl methacrylate) (PMMA), is also known by its commercial names such as Lucite, Perspex and Plexiglas. It is used as a sturdy substitute for glass for products such as aquariums, motorcycle helmet visors, aircraft windows, viewing windows of submersibles, and lenses of exterior lights of automobiles. It is widely used to make signs, including lettering and logos. In medicine, it is used in bone cement and to replace eye lenses. Acrylic paint consists of PMMA particles suspended in water.

Table 1 Various Properties of Polycarbonate Acrylic

\begin{tabular}{||l||l||}
\hline \hline Density & $1.20-1.22 \mathrm{~g} / \mathrm{cm}^{\wedge} 3$ \\
\hline \hline Refractive Index & $1.584-1.586$ \\
\hline \hline Water Absorption & $0.1 \%$ \\
\hline \hline Tensile Strength & $55-75 \mathrm{MPa}$ \\
\hline \hline Elongation & $\mathbf{8 0}-150 \%$ \\
\hline \hline Hardness Rockwell & $\mathrm{M70}$ \\
\hline \hline Izod Impact & $600-850 \mathrm{~J} / \mathrm{m}$ \\
\hline \hline Poisson's Ratio & 0.37 \\
\hline
\end{tabular}

\section{JOULE'S LAW OF HEATING}

The heat is formed due to current flowing in the wire, the amount of electric current flowing in the wire is directly proportional to square of the amount of the current flowing in the circuit I.e. $\mathrm{H}$ is directly proportional to the square of current flowing. Heat is generated due to the flow of current which is proportional to current flowing in the wire:

$\mathrm{H}$ is directly proportional to product of current(i) square resistance and time.

$\mathrm{H}=$ heat generated in joules.

$\mathrm{i}=$ current flowing in the wire.

$\mathrm{R}=$ resistance of the wire.

$\mathrm{j}=$ constant known as mechanical equivalent of heat.

$$
\text { Therefore, } H=\frac{I^{2} R t \text { Joules }}{4.2 \text { Joules } / \text { cal }}=\frac{I^{2} R t}{4.2} \mathrm{cal}=0.24 I^{2} R t \mathrm{cal}
$$

With the help of ohm's law we get

$$
H=0.24 V \text { It cal }=0.24 \frac{V^{2}}{R} \text { cal }(\text { as } V=I R)
$$

with joule's law of heating we can find the amount of heat energy provided by the wire in unit time when the process is going taking place.

Table 2. Relationship between Area of the visor and the Heat Generated.

\begin{tabular}{|l|l|l|}
\hline $\begin{array}{l}\text { Area of the Visor } \\
\text { (m square) }\end{array}$ & $\begin{array}{l}\text { Volume of the } \\
\text { Water(m cube) }\end{array}$ & $\begin{array}{l}\text { Heat } \\
\text { Generated }\end{array}$ \\
\hline $\mathbf{0 . 0 1 8 0}$ & $1.80 \times 10^{\wedge}-7$ & 406.8 Joules \\
\hline $\mathbf{0 . 0 1 3 5}$ & $1.35 \times 10^{\wedge}-7$ & 305.1 Joules \\
\hline $\mathbf{0 . 0 0 9 0}$ & $0.90 \times 10^{\wedge}-7$ & 203.4 Joules \\
\hline $\mathbf{0 . 0 0 5 0}$ & $0.50 \times 10^{\wedge}-7$ & 113.0 Joules \\
\hline $\mathbf{0 . 0 0 2 2}$ & $0.22 \times 10^{\wedge}-7$ & 68.8 Joules \\
\hline
\end{tabular}

Table 3. Relationship between Area of the visor and the time required to Heat of the mist.

\begin{tabular}{|l|l|}
\hline $\begin{array}{l}\text { Area of the Visor }(\mathbf{m} \\
\text { square) }\end{array}$ & $\begin{array}{l}\text { Time Required to Heat of } \\
\text { the Mist (minutes) }\end{array}$ \\
\hline $\mathbf{0 . 0 1 8}$ & 9.95 \\
\hline $\mathbf{0 . 0 1 3 5}$ & 7.74 \\
\hline $\mathbf{0 . 0 0 9}$ & 4.96 \\
\hline $\mathbf{0 . 0 0 5}$ & 3.25 \\
\hline $\mathbf{0 . 0 0 2}$ & 1.68 \\
\hline
\end{tabular}

Table 4. The relationship between Areas vs. Final Temperature of the Visor.

\begin{tabular}{|l|l|l|}
\hline $\begin{array}{l}\text { Area of the visor } \\
\text { needs to be heated } \\
\text { (m square) }\end{array}$ & $\begin{array}{l}\text { Heat Energy } \\
\text { (Joules) }\end{array}$ & $\begin{array}{l}\text { Final } \\
\text { Temperature in } \\
\text { degree Celsius }\end{array}$ \\
\hline $\mathbf{0 . 0 1 8 0}$ & 406.8 & 38.34 \\
\hline $\mathbf{0 . 0 1 3 5}$ & 305.1 & 35.11 \\
\hline $\mathbf{0 . 0 0 9}$ & 203.4 & 33.94 \\
\hline $\mathbf{0 . 0 0 5}$ & 113.4 & 32.94 \\
\hline $\mathbf{0 . 0 0 2}$ & 67.80 & 31.32 \\
\hline
\end{tabular}




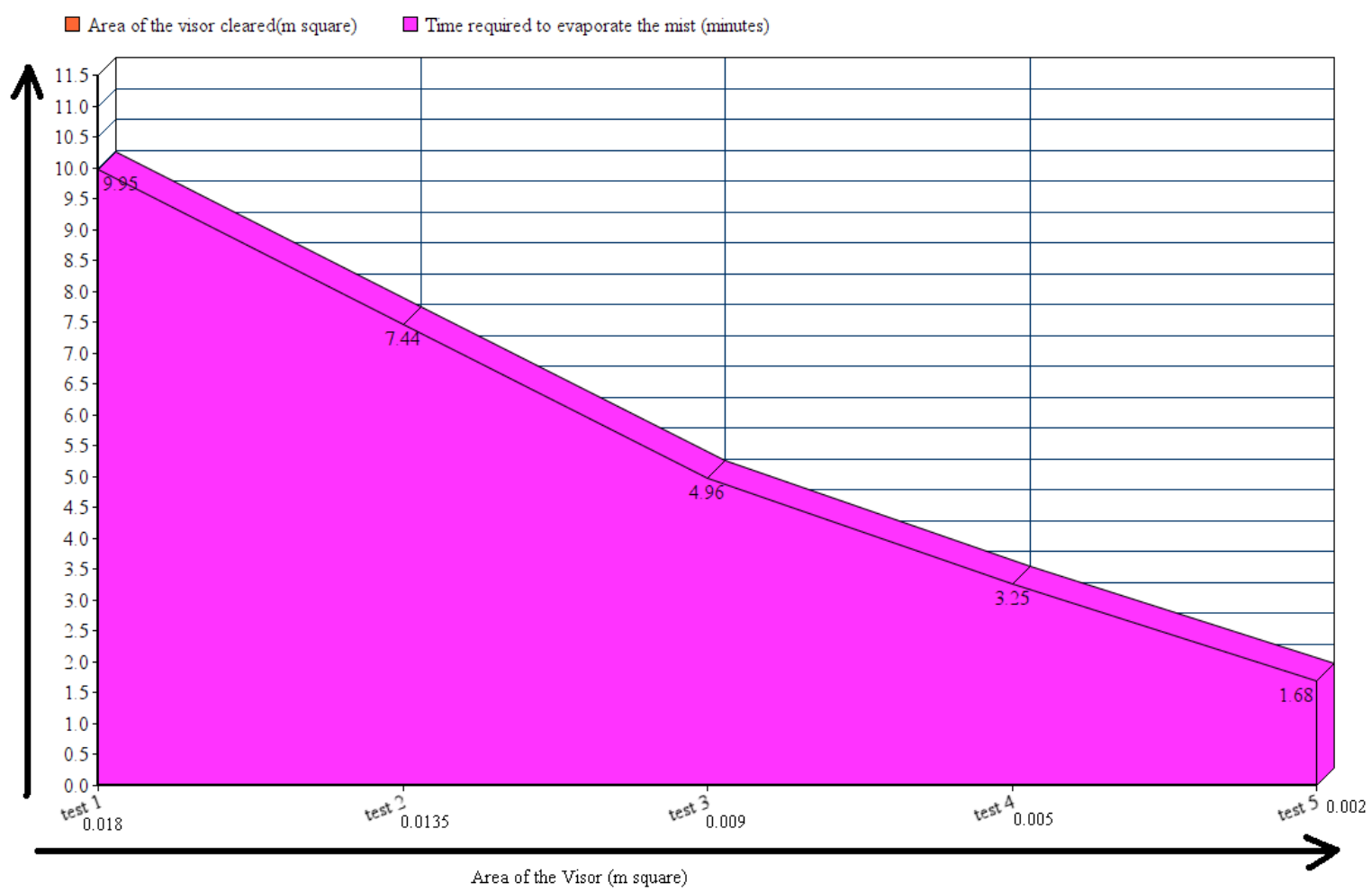

Figure 1: The graph represent the relationship between Time Required to Heat of the Mist (minutes) and Area of the Visor (m square).

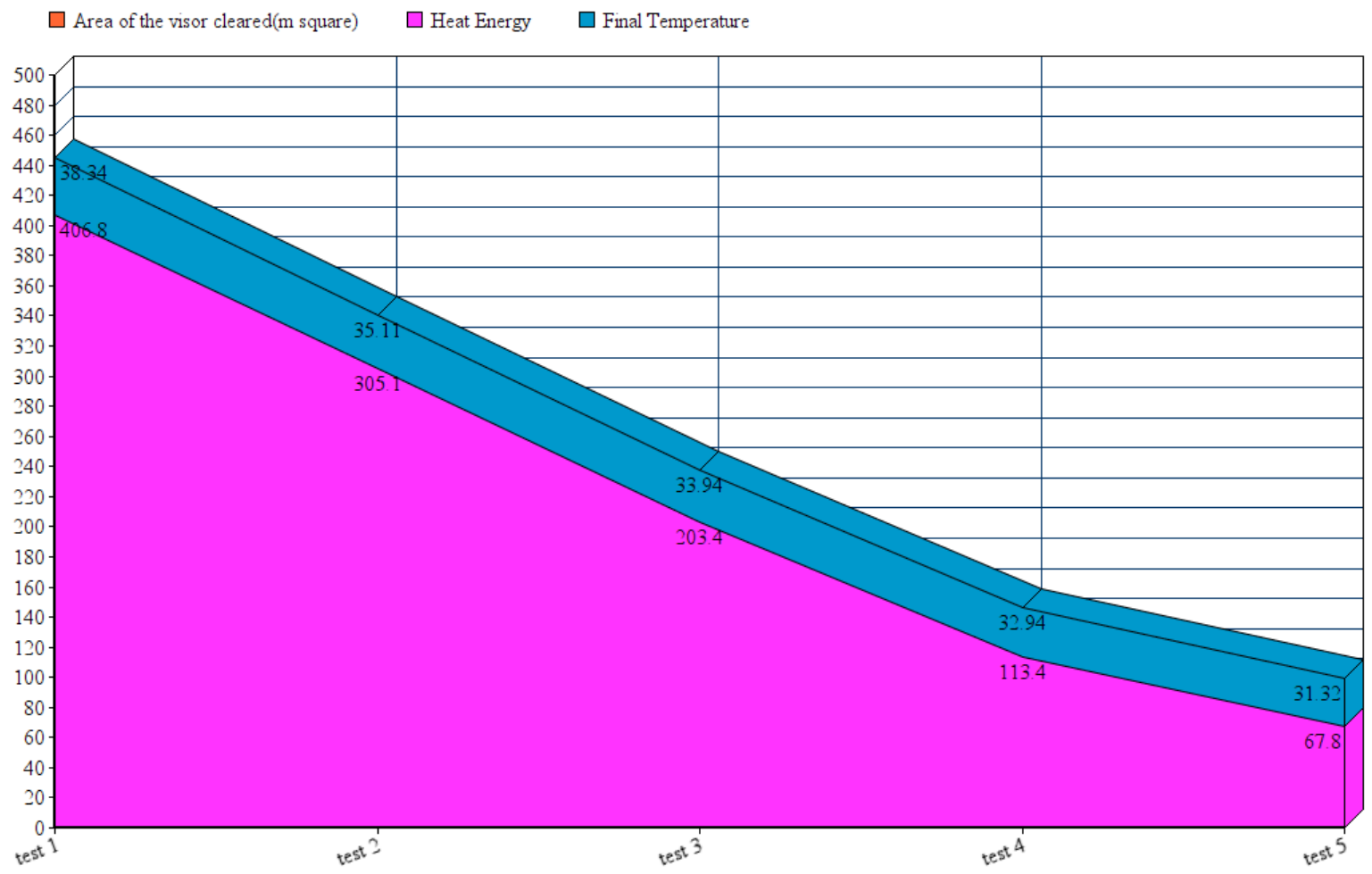

Figure 2: The graph represents the relationship between Areas vs. Final Temperature.

\section{DESIGN OF HELMET AND VISOR}

The feature based parametric modeling technique helps a designer to enable his designs into the original design content into constructing its desired model. The word parametric means the geometric definition of designs such as measurements that can be alter with respect to time. Processing and creating the main features of the design with the help of the computer software achieve parametric modeling. The design constant and variables are described in sketches and features can be used to quickly modify the designs. 


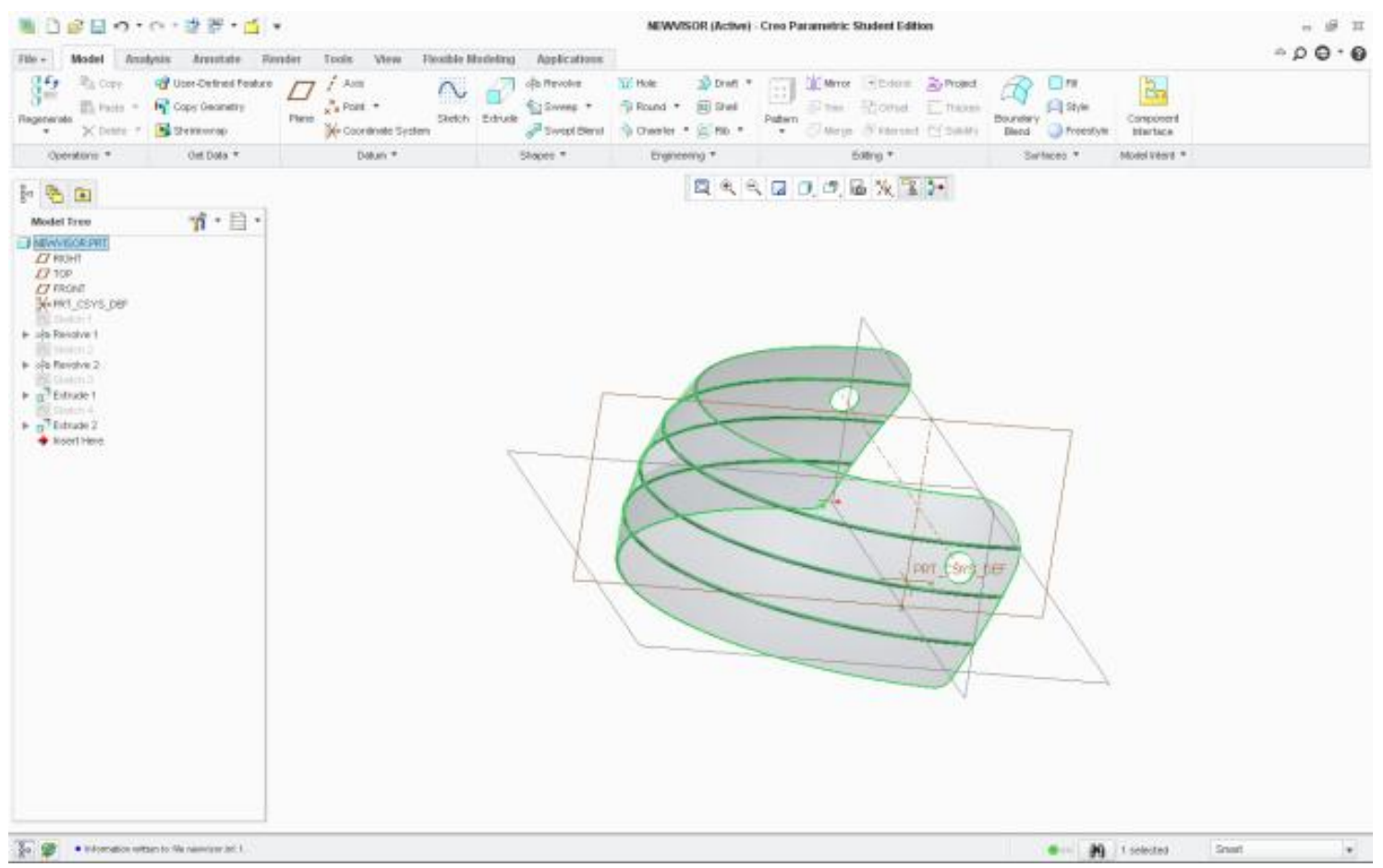

Figure3:The above image show case the all sections of the visor the three wires with diameter of $1 \mathrm{~mm}$ is bounded on the visor in equal interval of $40 \mathrm{~mm}$ on a total width of $159 \mathrm{~mm}$.

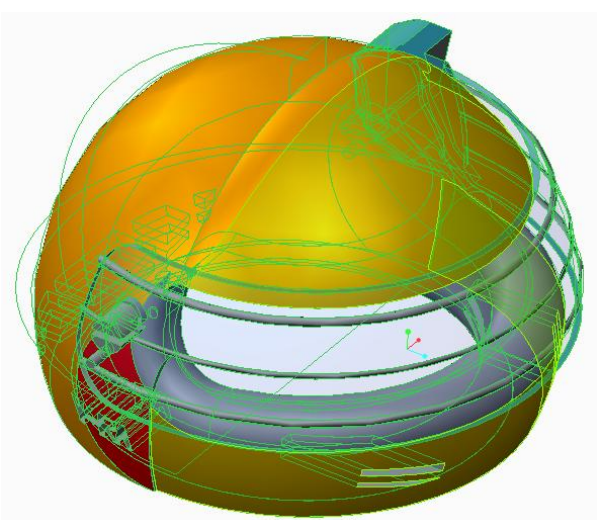

Figure 4: The final finished product after design modeling in Creo 2.0

\section{THERMAL ANALYSIS OF THE HELMET}

\section{AND VISOR}

A thermal analysis calculates the temperature distribution and thermal quantities in or of a system the usual thermal quantities are specified the temperature distributions, the amount of heat formed or dissipated, Thermal gradients and Thermal fluxes.

Thermal simulations are important in designing of many engineering applications, including internal combustion engines, turbine, heat exchangers, piping systems and electronic components. In cases, engineers follow a thermal analysis to calculate with stress analysis to calculate thermal analysis.

Steady-state thermal analysis also can be the last step of a transient thermal analysis; performed after all transient effects have gone. Use steady-state thermal analysis to find out temperatures, thermal gradients, heat flow rates, and heat fluxes in an object that are caused by thermal load in the model. These loads include:

- Convections

\section{RADIATION}

- Heat flow rates

- Heat fluxes (heat flow per unit area)

- Heat generation rates (heat flow per unit volume)

- Constant temperature boundaries

\section{Solution for Visor Thermal Analysis in:}

- Temperature

- Total Heat Flux

- Directional Heat Flux

Besides steady state analysis it also performs transient thermal analysis follows basically the same steps as a steady-state thermal analysis. The maincomparison is that most applied loads in a transient analysis are functions of time. To specify time-dependentloads, we can either use the Function Tool to define an equation or function describing the curve or then applythe function as a boundary condition, or we can divide the load-versus-time curve into load. After analysis the file is saved in .wbpj file format.

\section{RESULT\&DISCUSSION}

The following three images shows the results of thermal analysis in

- Temperature

- Total Heat Flux

- Directional Heat Flux 


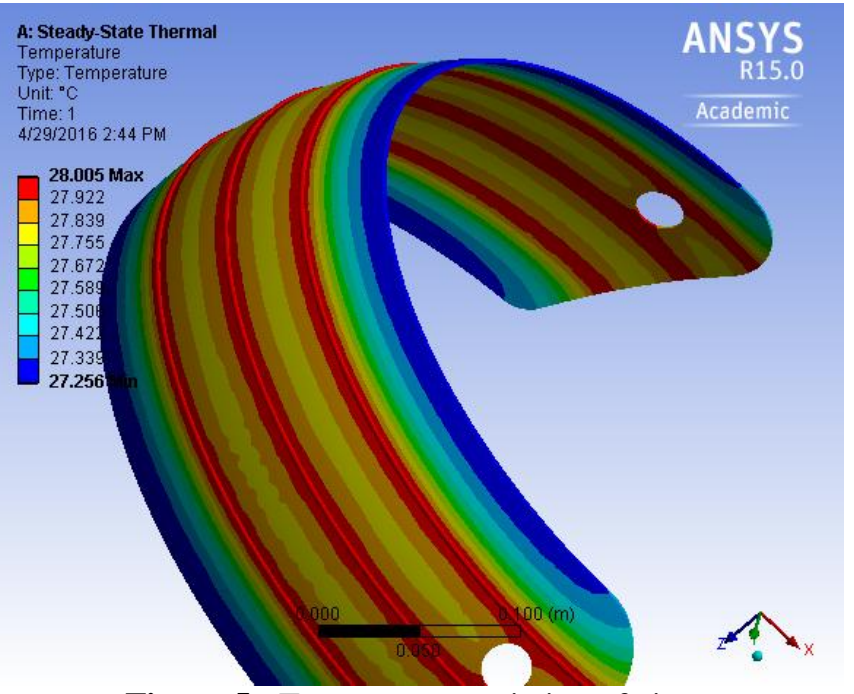

Figure 5 : Temperature variation of visor

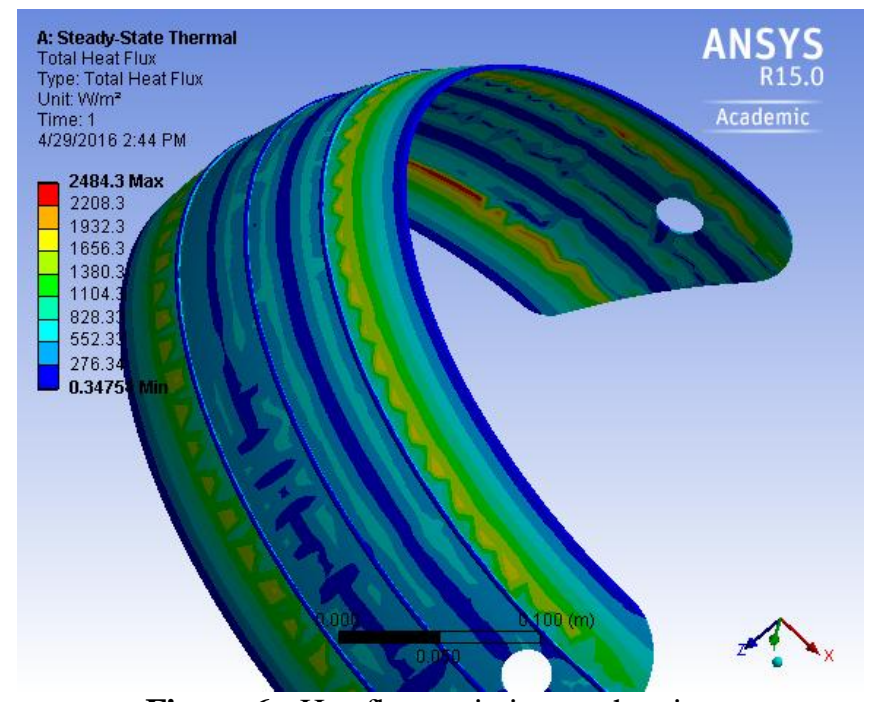

Figure 6 : Heatflux variation on the visor

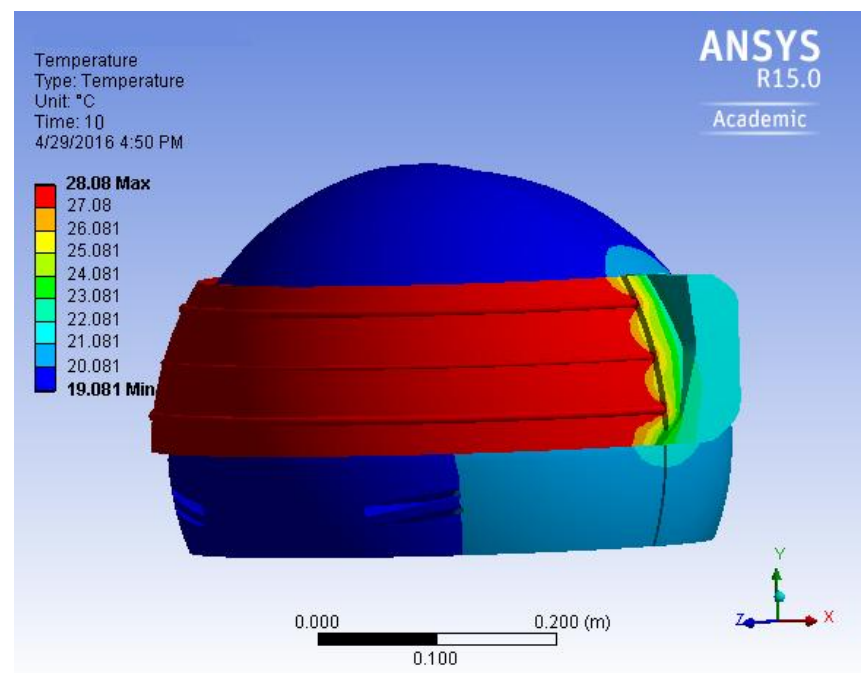

Figure 7: Heat Fluxof Helmet and visor after $60 \mathrm{sec}$.

From ANSYS thermal analysis the result showed the heating element heats the visor throughout the visor with a steady and clear heat distribution without any fluctuations in heat the temperature heat flux and directive heat flux are all shown in results, proves that the model will hold steady in a cold weather with high fog density, after analysis is completed thermal imaging of the model delivers a heat of 28 degree Celsius for $60 \mathrm{sec}$ in surrounding ambient temperature of 5 degree Celsius smoothly. The helmet is worn and it shows great improvements in practical situations however power source is the main issue but for performance it can be increased.

\section{CONCLUSION}

The report projects the analysis of the fog removal system to its utmost content analysis being done on the Ansys shows us temperature and heat flux variations joules law and convection with conservation of energy, Creo provides us with perfect modeling of Helmet and visor while joules law helps us to calculate the heat energy from the current flowing in the visor. Care has been taken in all mathematical calculation. Also rider's safety and comfort is also taken care of so as not only it provides safety but also feeling of comfort efforts have been made on reducing cost and increasing effectiveness of the system.

\section{REFRENCE}

[1]. Holdeman, J.T. "A Hermite finite element method for incompressible fluid flow", Int. J. Numer. Meth. (2010),

[2]. Ladyzhenskaya, O.A., The Mathematical Theory of viscous Incompressible Flow (2nd ed.) (1969)

[3]. Flake C. Campbell, A Elements of Metallurgy and Alloys, (1 ${ }^{\text {st }}$ ed.) 2008

[4]. Emadi, D; L. V. Whiting; S. Nafisi; R. Ghomashchi Journal of Thermal Analysis and Calorimetry (2005).

\section{BIOGRAPHIES}

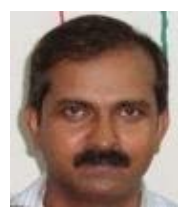

Mr. Vivek Verma, Assistant Professor, Mechanical and Automation Engineering. Amity University, Lucknow and vverma@lko.amity.edu

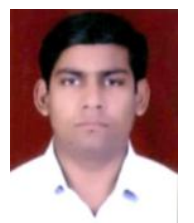

Mr. Ashwani Sharma, Assistant Professor, Mechanical and Automation Engineering. Amity University, Lucknow and ashwani28585@gmail.com

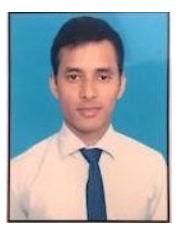

Ashwini Kumar Shrivastava, UG Student of Mechanical and Automation Engineering, Amity University, Lucknow, and ash96shrivastava@gmail.com

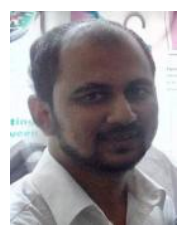

Himal Hazra, UG Student of Mechanical and Automation Engineering, Amity University, Lucknow and mercuwings@gmail.com 